\title{
Markus K. Heinemann: How NOT to write a medical paper: a practical guide
}

\author{
2016. Thieme Medical and Scientific Publishers Private Limited, India, ISBN 978-93-85062-29- \\ 2, 95 pages
}

\author{
Fabrice Duparc ${ }^{1}$ (1)
}

Received: 4 December 2017 / Accepted: 5 December 2017 / Published online: 21 December 2017

(c) Springer-Verlag France SAS, part of Springer Nature 2017

The author is the Editor in Chief of The Thoracic and Cardiovascular Surgeon, organ of the German Society for Thoracic and Cardiovascular Surgery. He used his editorial experience for building this short but very concise book, with numerous characteristic examples in each section that could also be named "How to avoid a submission to be rejected".

The first section is "Why editors accept/reject manuscripts?" It presents the top10 reasons of rejection, and the ten main reasons of acceptability. We could add the problem of the manuscript that does not deal with the goals of the journal, as a maladjusted submission. It is well explained that "the reviewers will dissect the paper", and the peers review will look for detecting possibilities for improvement.

The second section presents the types of scientific articles: original article, meta-analysis, and review articles, case reports, letter to the editor, and insists about the mandatory respect given to the guidelines.

The third section explains the manuscript components: number of co-authors, "contributors" whose names can be listed in the Acknowledgement section-title-abstract and key words-introduction-material and methods, statistics—results—discussion-conclusion. It insists about the care given to the Instructions for authors as "the first step to the success".

The fourth section describes the review process and corrections, and emphasizes the importance of the point by point reply to the reviewers' suggestions.

A special section is devoted to the publications ethics, the problems of duplicate submissions, "salami" submissions of parts of a same study, and disclosures.

A section "good do know" summarizes the procedure after acceptance of the manuscript: production chain, production editor, typesetter, building of the proofs-corresponding author-indexing, factors-role of publishers, supporting the journal, plagiarism search, subscriptions, marketing and distribution, open access.

A list of 26 references is provided. A 5 page index allows a quick access to the different topics.

This small book must be recommended for all the authors of medical papers and researchers, before submitting any manuscript, but is also rich of advices that may be of interest for reviewers and editors.
Fabrice Duparc

fabrice.duparc@univ-rouen.fr

1 Universite de Rouen, Rouen, France 